\title{
Draft genome sequence and characterization of Desulfitobacterium hafniense PCE-S
}

\author{
Tobias Goris ${ }^{1 *}$, Bastian Hornung ${ }^{2,3}$, Thomas Kruse ${ }^{2}$, Anika Reinhold ${ }^{1}$, Martin Westermann ${ }^{4}$, Peter J Schaap ${ }^{3}$, \\ Hauke Smidt ${ }^{2}$ and Gabriele Diekert ${ }^{1}$
}

\begin{abstract}
This genome report describes the draft genome and the physiological characteristics of Desulfitobacterium hafniense PCE-S, a Gram-positive bacterium known to dechlorinate tetrachloroethene (PCE) to dichloroethene by a PCE reductive dehalogenase. The draft genome has a size of $5,666,696$ bp with a $\mathrm{G}+\mathrm{C}$ content of $47.3 \%$. The genome is very similar to the already sequenced Desulfitobacterium hafniense Y51 and the type strain DCB-2. We identified two complete reductive dehalogenase $(r d h)$ genes in the genome of $D$. hafniense PCE-S, one of which encodes PCeA, the PCE reductive dehalogenase, and is located on a transposon. Interestingly, this transposon structure differs from the PceA-containing transposon of D. hafniense Y51. The second $r d h$ encodes an unknown reductive dehalogenase, highly similar to rdhA 7 found in D. hafniense DCB-2, in which the corresponding gene is disrupted. This reductive dehalogenase might be responsible for the reductive dechlorination of 2,4,5-trichlorophenol and pentachlorophenol, which is mediated by $D$. hafniense PCE-S in addition to the reductive dechlorination of PCE.
\end{abstract}

Keywords: Anaerobic respiration, Organohalide respiration, Reductive dechlorination, Chlorinated ethenes, Chlorinated phenols, Bioremediation, Reductive dehalogenase

\section{Introduction}

Desulfitobacterium spp. are anaerobic Gram-positive bacteria belonging to the phylum Firmicutes. Desulfitobacteria are metabolically versatile bacteria capable of utilizing a wide range of electron donors and acceptors, the latter also including organohalides. Previously, the genome sequences of Desulfitobacterium hafniense Y51 and DCB-2 have been published [1,2], and further genomes of various desulfitobacteria are expected to be published in the near future as the result of ongoing sequencing projects (Kruse et al, unpublished results). The genomes of Desulfitobacterium hafniense DCB-2 and Y51 are relatively large (5.3 and $5.7 \mathrm{Mbp}$, respectively) and are characterized by a high number of genes related to energy metabolism. In both genomes, at least one gene encoding a reductive dehalogenase was found. $D$. hafniense DCB-2 contains seven $r d h$ genes, two of which are likely non-functional due to either a transposase insertion or a

\footnotetext{
*Correspondence: tobias.goris@uni-jena.de

'Institut für Mikrobiologie, Lehrstuhl für Angewandte und Ökologische Mikrobiologie, University of Jena, Philosophenweg 12, Jena D-07743, Germany

Full list of author information is available at the end of the article
}

frameshift mutation. The D. hafniense Y51 genome harbours one reductive dehalogenase gene, encoding a PCE reductive dehalogenase [1]. Despite the great interest in the potential application of Desulfitobacterium spp. and other organohalide-respiring bacteria for bioremediation, only a few reductive dehalogenases have been biochemically characterized. One example of a well-studied reductive dehalogenase is the tetrachloroethene reductase, PceA, from $D$. hafniense PCE-S [3-6].

Here, we describe the isolation and characterization of $D$. hafniense PCE-S together with its draft genome sequence. The organism is capable of dechlorinating PCE via TCE to cis-DCE as well as of several chlorophenols. The draft genome is $5,666,696 \mathrm{bp}$ in size and is compared to the genome sequences of D. hafniense Y51 and DCB-2. In addition, some morphological and physiological characteristics of strain PCE-S are given and compared to those of other members of the Desulfitobacterium genus.

\section{Organism information Characterization and features \\ Desulfitobacterium hafniense (Figure 1) PCE-S was isolated from a fixed-bed reactor inoculated with a methanogenic}

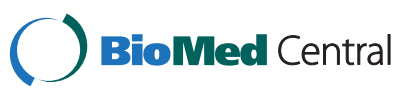

(c) 2015 Goris et al.; licensee BioMed Central. This is an Open Access article distributed under the terms of the Creative Commons Attribution License (http://creativecommons.org/licenses/by/4.0), which permits unrestricted use, distribution, and reproduction in any medium, provided the original work is properly credited. The Creative Commons Public Domain Dedication waiver (http://creativecommons.org/publicdomain/zero/1.0/) applies to the data made available in this article, unless otherwise stated. 


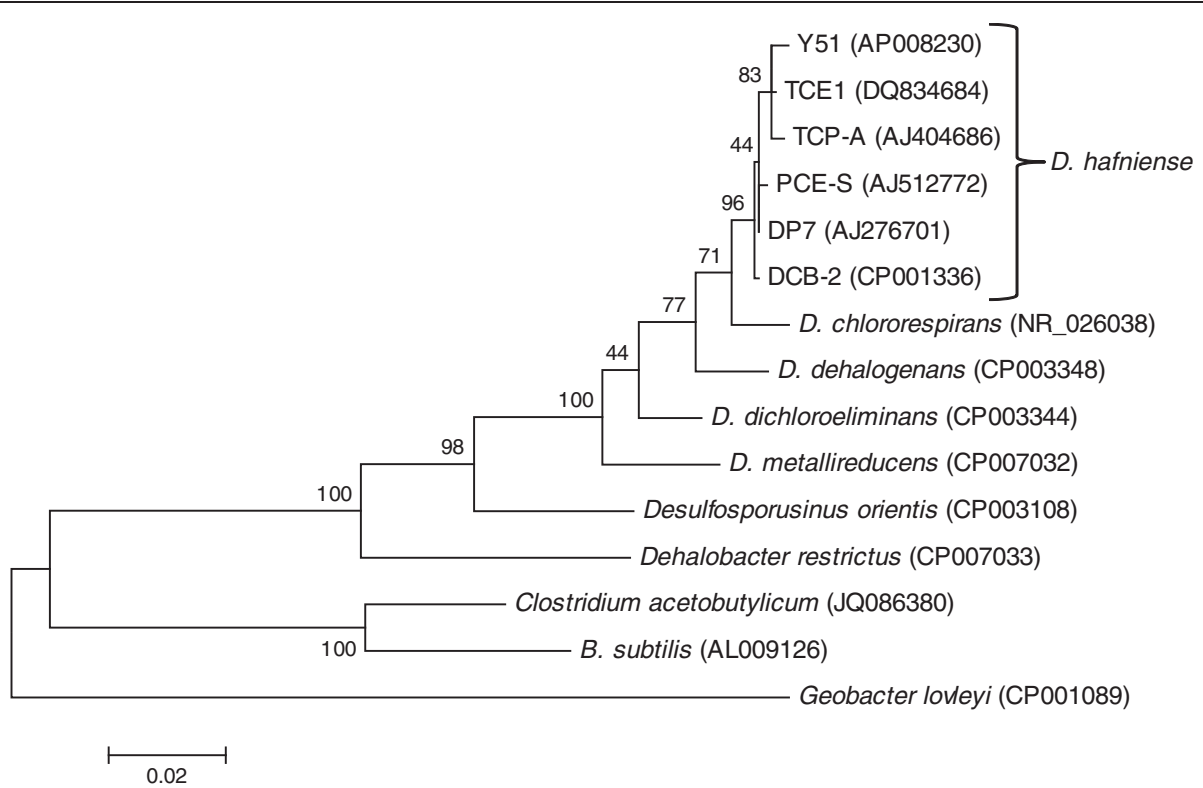

Figure 1 Phylogenetic tree of Desulfitobacterium spp. 16S rRNA gene sequences were derived from NCBI Genbank. The following 165 rRNA genes were chosen if a complete genome sequence was available: Bacillus subtilis: BSU_rRNA_4, Geobacter lovleyi: Glov_R0005, Desulfosporosinus orientis: Desor_0097, D. dehalogenans: Desde_0132; D. dichloroeliminans: Desdi_0096, D. metallireducens: DESME_00460; D. hafniense Y51: DSY_16SrRNA1; D. hafniense DCB-2: Dhaf_R0006; Dehalobacter restrictus: DEHRE_01135. D. hafniense PCE-S 16S rRNA gene sequence: was corrected with the help of the draft genome sequence. The tree was generated with MEGA 6.0 [7] using the maximum likelihood algorithm with 500 bootstraps and standard settings. Sequences were trimmed to the size of the shortest available sequence and aligned with Muscle. Bootstrap values of lower than $70 \%$ are considered as low and thus the two nodes with low bootstrap values in the Desulfitobacterium clade have to be considered with care.

mixed culture, enriched from soil of a dumping site contaminated with chlorinated ethenes. For further enrichment, the mixed culture was immobilized in a fixed-bed reactor with anoxic mineral medium supplemented with $20 \mathrm{mmol} \mathrm{l}^{-1}$ ethanol and 0.4 to $0.5 \mathrm{mmol} \mathrm{l}^{-1}$ PCE. A pure culture was obtained by inoculating agar medium in roll tubes with a diluted suspension of the biofilm. D. hafniense PCE-S has been deposited in the German Collection of Microorganisms and Cell Cultures (DSM 14645).

$D$. hafniense PCE-S is a slightly curved, sporulating Gram-positive rod of $0.6 \mu \mathrm{m}$ (diameter) by $6.0 \mu \mathrm{m}$ (length). Motility was observed only during exponential

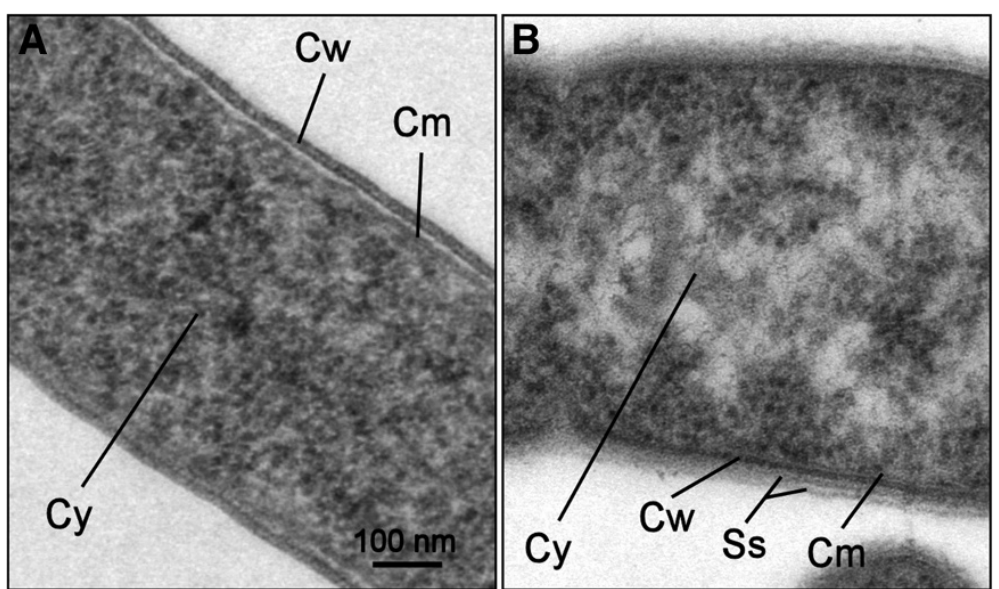

Figure 2 Ultra-thin section electron micrograph of cells of D. hafniense Y51 (A) and PCE-S (B). Cm: cytoplasmic membrane, CW: cell wall, Cy: cytoplasm, Ss: slime sacculus (mucosal layer). Cells were grown in the presence of PCE and harvested in the late exponential growth phase. Cells were pre-fixed with $2.5 \%$ glutaraldehyde for $1 \mathrm{~h}$ and post fixed with $1 \%$ osmium tetroxide for $2 \mathrm{~h}$. Samples were dehydrated in ascending ethanol series and embedded in Araldite resin. Ultra-thin sections were prepared with an ultramicrotome (Ultratome III, LKB Produkter AB, Bromma, Sweden) and analysed in a Zeiss EM902A transmission electron microscope (Carl Zeiss AG, Oberkochen, Germany). 
growth. The cells are surrounded by a slime sacculus, a trait that distinguishes $D$. hafniense PCE-S from $D$. hafniense Y51 (Figure 2). Cytochromes $b$ and $c$ as well as corrinoids, the latter being an essential cofactor of reductive dehalogenases, were detected in strain PCE-S.

$D$. hafniense PCE-S was shown to utilize pyruvate and several O-methylated compounds (Table 1, [8,9]) as electron donor, whereas acetate, glucose, fructose, mannitol or sorbitol were not utilized as electron donor. Fumarate, nitrate, thiosulfate and several chlorinated compounds were used as electron acceptors (Table 1). In addition, fermentation of pyruvate as sole energy

Table 1 Classification and general features of Desulfitobacterium hafniense PCE-S

\begin{tabular}{|c|c|c|c|}
\hline MIGS ID & Property & Term & $\begin{array}{l}\text { Evidence } \\
\text { code }^{a}\end{array}$ \\
\hline & \multirow[t]{8}{*}{ Classification } & Domain Bacteria & TAS [10] \\
\hline & & Phylum Firmicutes & TAS [11] \\
\hline & & Class Clostridia & $\operatorname{TAS}[12,13]$ \\
\hline & & Order Clostridiales & TAS [14] \\
\hline & & Family Peptococcaceae & $\operatorname{TAS}[13,15]$ \\
\hline & & Genus Desulfitobacterium & TAS [16] \\
\hline & & $\begin{array}{l}\text { Species Desulfitobacterium } \\
\text { hafniense }\end{array}$ & TAS [17] \\
\hline & & Strain PCE-S & \\
\hline & Gram stain & Negative & IDA \\
\hline & Cell shape & Curved Rods & IDA \\
\hline & Motility & $\begin{array}{l}\text { + (only exponentially } \\
\text { growing cells) }\end{array}$ & IDA \\
\hline & Sporulation & + & IDA \\
\hline & Temperature range & $20-45^{\circ} \mathrm{C}$ & IDA \\
\hline & Optimum temperature & $37^{\circ} \mathrm{C}$ & IDA \\
\hline & pH range; Optimum & not determined & \\
\hline & Carbon source & Pyruvate, acetate & IDA \\
\hline MIGS-6 & Habitat & $\begin{array}{l}\text { Soil contaminated with } \\
\text { chlorinated ethenes }\end{array}$ & IDA \\
\hline MIGS-6.3 & Salinity & not determined & \\
\hline MIGS-22 & Oxygen requirement & $\begin{array}{l}\text { Anaerobic, } \\
\text { Microaerotolerant }\end{array}$ & NAS \\
\hline MIGS-15 & Biotic relationship & free-living & IDA \\
\hline MIGS-14 & Pathogenicity & None known & IDA \\
\hline MIGS-4 & Geographic location & Eppelheim, Germany & IDA \\
\hline MIGS-5 & Sample collection time & 1996 & IDA \\
\hline MIGS-4.1 & Latitude & 49.39 & IDA \\
\hline MIGS-4.2 & Longitude & 8.62 & IDA \\
\hline MIGS-4.4 & Altitude & $110 \mathrm{~m}$ & IDA \\
\hline
\end{tabular}

a) Evidence codes - IDA: Inferred from Direct Assay; TAS: Traceable Author Statement (i.e., a direct report exists in the literature); NAS: Non-traceable

Author Statement (i.e., not directly observed for the living, isolated sample, but based on a generally accepted property for the species, or anecdotal evidence). These evidence codes are from the Gene Ontology project [18].
Table 2 Project information

\begin{tabular}{lll}
\hline MIGS ID & Property & Term \\
\hline MIGS-31 & Finishing quality & $\begin{array}{l}\text { Improved high quality draft } \\
\text { One Illumina Miseq paired } \\
\text { end library }\end{array}$ \\
MIGS-29 & Libraries used & $\begin{array}{l}\text { Illumina MiSeq Personal } \\
\text { Sequencer }\end{array}$ \\
MIGS-31.2 & Fold coverage & 100 $\times$ \\
MIGS-30 & Assemblers & Ray version 2.3, Edena \\
& & version 3.130110 \\
MIGS-32 & Gene calling method & Prodigal version 2.5 \\
& Locus Tag & DPCES \\
& EMBL ID & LK996017-LK996040 \\
& EMBL Date of Release & September 31, 2014 \\
& GOLD ID & Gp0109025 \\
& BIOPROJECT & 264037 \\
& Project relevance & Bioremediation \\
MIGS 13 & Source Material Identifier & DSM 14645 \\
\hline
\end{tabular}

substrate supports growth of D. hafniense PCE-S. Growth in liquid media was observed at temperatures ranging from $20^{\circ} \mathrm{C}$ to $45^{\circ} \mathrm{C}$ with an optimum at $37^{\circ} \mathrm{C}$ (Table 1). With pyruvate as electron donor and PCE as electron acceptor, the maximal dechlorination rate was observed at $\mathrm{pH}$ 7.7.

With PCE as electron acceptor $(20 \mathrm{mM}$, supplied from a hexadecane phase), pyruvate was oxidized to acetate and PCE was dechlorinated to cis,1,2-dichloroethene as the main dechlorination product $(\geq 95 \%)$ and minor amounts of trichloroethene $(\leq 5 \%)$. The chlorinated ethenes were determined gas chromatographically with $\mathrm{N}_{2}$ as carrier gas using two bonded-phase fused silica capillary columns.

The generation time of growth with pyruvate as electron donor and PCE as electron acceptor was $10 \mathrm{~h}$ without and $8 \mathrm{~h}$ with $0.1 \%$ yeast extract at $30^{\circ} \mathrm{C}$. Fumarate as electron acceptor plus yeast extract led to a slightly shorter generation time $(7 \mathrm{~h})$ than with $\mathrm{PCE} /$ yeast extract.

The ability of $D$. hafniense PCE-S to dechlorinate polychlorinated phenols was investigated with pyruvate as electron donor and $0.1 \%$ yeast extract. Chlorophenols were analysed by HPLC using an RP-18 $(5 \mu \mathrm{m})$ LiChrospher 100 column (Merck, Darmstadt, Germany). Pentachlorophenol and 2,4,5-trichlorophenol at a concentration of $20 \mu \mathrm{mol} \mathrm{l}^{-1}$ in mineral medium were dechlorinated. 2,4,5-trichlorophenol was partially dechlorinated to 3,4-dichlorophenol, pentachlorophenol was partially dechlorinated to 3,4-dichlorophenol and an unidentified tetrachlorophenol. 2,6-dichlorophenol, 3,5-dichlorophenol, and 2,4-dichlorophenol were not dechlorinated by $D$. hafniense PCE-S. 


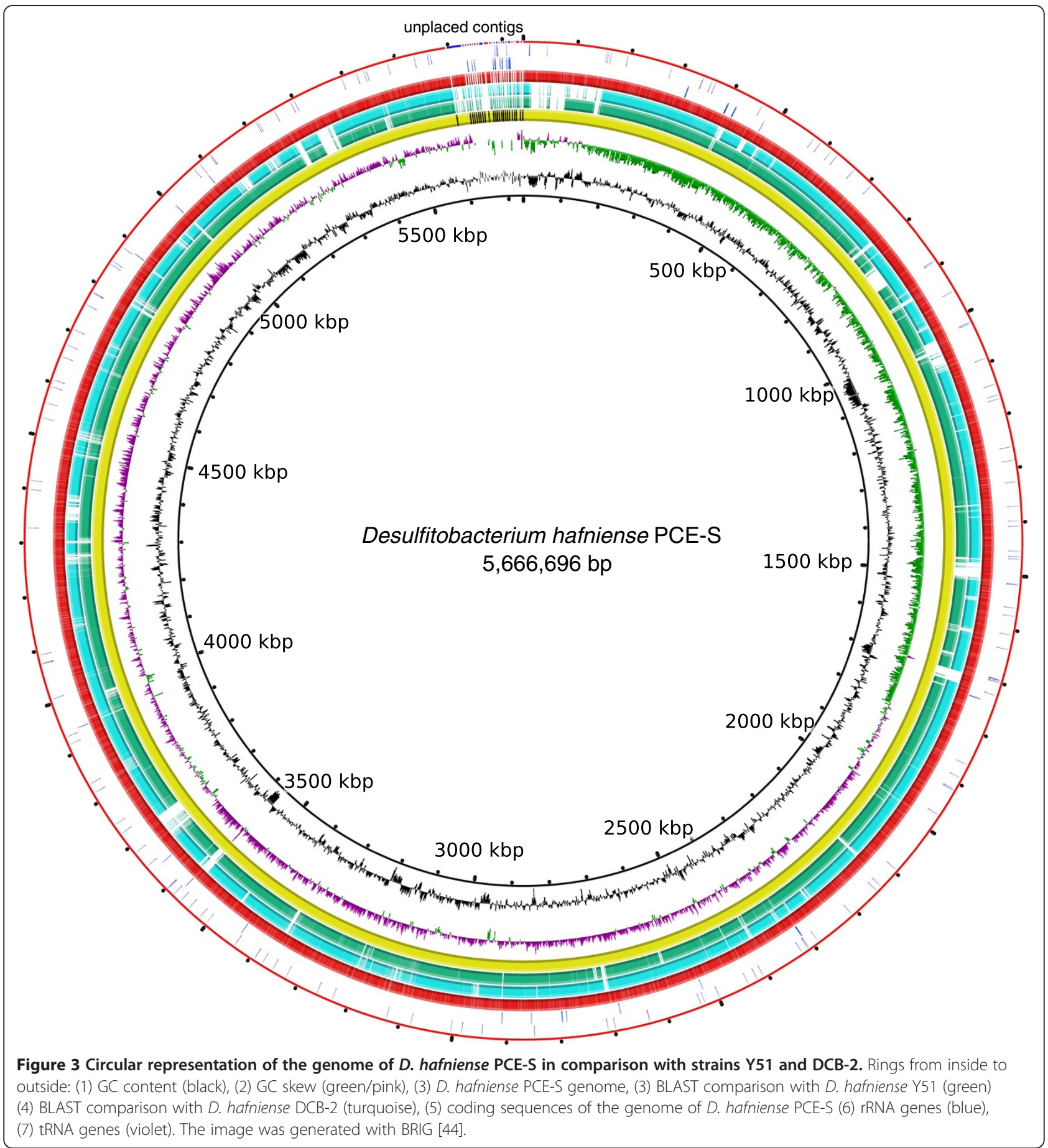

D. hafniense PCE-S has an average nucleotide identity (ANI) of $98.25 \%$ to D. hafniense Y51 and of 97.6 to the D. hafniense type strain DCB-2 $[1,2,19]$.

\section{Genome sequencing information}

\section{Genome project history}

The genome consists of 101 contigs in 24 scaffolds, of which the largest scaffold consists of 5,594,916 bp, covering more than $98 \%$ of the genome and more than $98 \%$ of the protein coding genes. Table 2 presents the project information and its association with MIGS version 2.0 compliance [20].

\section{Growth conditions and DNA preparation}

$D$. hafniense PCE-S was cultivated under anoxic conditions as described by Scholz-Muramatsu et al. [21] and 
Table 3 Nucleotide content and gene count levels of the genome

\begin{tabular}{lll}
\hline Attribute & \multicolumn{2}{l}{ Genome (total) } \\
\cline { 2 - 3 } & Value & \% of total ${ }^{\mathbf{a}}$ \\
\hline Genome size (bp) & $5,666,696$ & $99.14^{\mathrm{b})}$ \\
DNA Coding & $4,904,707$ & 86.55 \\
DNA G + C (bp) & $2,679,309$ & 47.3 \\
DNA scaffolds & 24 & 100 \\
Total genes & 5,494 & 100 \\
Protein-coding genes & 5,417 & 98.47 \\
RNA genes & 80 & 1.42 \\
Pseudogenes & not determined & not determined \\
Genes in internal clusters & not determined & not determined \\
Genes with function prediction & 4561 & 83.02 \\
Genes assigned to COGs & 3,210 & 58.26 \\
Genes with Pfam domains & 4387 & 79.85 \\
Genes with signal peptides & 296 & 5.46 \\
Genes with transmembrane helices & 1,624 & 29.98 \\
CRISPR repeats & 143 & \\
\hline
\end{tabular}

${ }^{a}$ The total is based on either the size of the genome in base pairs or the total number of protein coding genes in the annotated genome.

b) Percent value of the draft genome sequence compared to the calculated size of the complete genome sequence.

Reinhold et al. [22]. For isolation of genomic DNA, $D$. hafniense PCE-S was cultivated for one subculture with fumarate after regularly being cultivated in the presence of PCE. The isolation was carried out as described by Reinhold et al. Approximately $12 \mu \mathrm{g}$ of genomic DNA were used for genome sequencing. The genome sequence of Desulfitobacterium hafniense PCE-S has been deposited in the EMBL database under accession numbers LK996017-LK996040.

\section{Genome sequencing and annotation}

DNA was sequenced at GATC Biotech (Konstanz, Germany) on an Illumina MiSeq Personal Sequencer, generating 1,242,269 paired end reads with a length of $250 \mathrm{bp}$.

Genome size was estimated prior to assembly using kmer spectrumanalyzer .

The assembly was done in parallel with two different assemblers. One assembly was performed with Edena [23], with standard parameters, the second assembly with Ray, using a kmer-value of 125 [24]. Afterwards both assemblies were merged with Zorro with one of the paired end files supplied [25]. Next, this hybrid assembly was scaffolded with opera version 1.2 [26], which was set up to use Bowtie version 0.12.7 for mapping [27]. As last step, Pilon version 1.4 was used for quality assurance on the assembly [28]. Reads were mapped with Bowtie2 version 2.0.6 [29], further converted with Samtools version
Table 4 Number of genes associated with the $\mathbf{2 5}$ general COG functional categories

\begin{tabular}{|c|c|c|c|}
\hline Code & Value & $\%$ of total ${ }^{\mathrm{a}}$ & Description \\
\hline J & 164 & 3.03 & Translation \\
\hline A & 0 & 0 & RNA processing and modification \\
\hline K & 279 & 5.15 & Transcription \\
\hline L & 168 & 3.10 & Replication, recombination and repair \\
\hline B & 1 & 0.02 & Chromatin structure and dynamics \\
\hline D & 37 & 0.68 & Cell cycle control, mitosis and meiosis \\
\hline Y & 0 & 0 & Nuclear structure \\
\hline V & 81 & 1.50 & Defense mechanisms \\
\hline T & 169 & 3.12 & Signal transduction mechanisms \\
\hline M & 127 & 2.34 & Cell wall/membrane biogenesis \\
\hline N & 57 & 1.05 & Cell motility \\
\hline Z & 1 & 0.02 & Cytoskeleton \\
\hline W & 0 & 0 & Extracellular structures \\
\hline U & 47 & 0.87 & Intracellular trafficking and secretion \\
\hline O & 85 & 1.57 & $\begin{array}{l}\text { Posttranslational modification, protein } \\
\text { turnover, chaperones }\end{array}$ \\
\hline C & 237 & 4.38 & Energy production and conversion \\
\hline G & 127 & 2.34 & Carbohydrate transport and metabolism \\
\hline$E$ & 312 & 5.76 & Amino acid transport and metabolism \\
\hline $\mathrm{F}$ & 66 & 1.22 & Nucleotide transport and metabolism \\
\hline $\mathrm{H}$ & 139 & 2.57 & Coenzyme transport and metabolism \\
\hline I & 77 & 1.42 & Lipid transport and metabolism \\
\hline$P$ & 214 & 3.95 & Inorganic ion transport and metabolism \\
\hline Q & 73 & 1.35 & $\begin{array}{l}\text { Secondary metabolites biosynthesis, } \\
\text { transport and catabolism }\end{array}$ \\
\hline $\mathrm{R}$ & 415 & 7.66 & General function prediction only \\
\hline S & 280 & 5.17 & Function unknown \\
\hline - & 2,261 & 41.74 & Not in COGs \\
\hline
\end{tabular}

a) The total is based on the total number of protein coding genes in the annotated genome.

0.1.18 (r982:295) [30], and then provided to Pilon as input data.

All steps were done using standard parameters, unless stated otherwise. Before annotation, the genome was blasted [31] against itself with an e-value of 0.0001. All contigs with a length of less than $500 \mathrm{bp}$ were discarded, as well as those with less than 1,000 bp which matched onto another genomic location with $100 \%$ identity.

After annotation, a check for technical duplications was performed. Contigs, which were determined to be such duplications, were manually removed from the initial assembly and replaced with contigs from the second assembler. The assembly workflow was repeated until no more technical duplications were found.

The assembly was then further scaffolded with CONTIGuator version 2.7.4 [32] and the genome of 
Desulfitobacterium hafniense Y51 as reference [1]. Disagreements with the reference genome were examined with Mauve [33] and Tablet [34], and in case of considerable drops of coverage, the contigs and related reads were isolated, and a re-assembly was performed with Edena. This re-assembly was again scaffolded with CONTIGuator using Y51 as reference genome. Non-scaffolded contigs were included as single contigs in the final result, unless they had a blast hit of more than $90 \%$ of their length with a minimum sequence identity of $90 \%$ to the scaffold result from CONTIGuator.

The annotation was carried out with an in-house pipeline. In short, this pipeline includes Prodigal version 2.5 for open reading frame identification [35], InterproScan version 5RC7 for protein annotation [36], tRNAscan SE 1.3.1 for tRNA identification [37] and rnammer 1.2 for the prediction of rRNAs [38]. Additional protein function predictions were derived via BLAST [39] UniRef50 and [40] Swissprot databases (downloaded August 2013) [41]. After the annotation process, EC numbers were added with PRIAM version March 06, 2013 [42]. COG assignments were created via blastp best bidirectional hit assignments [43].

\section{Genome properties}

The genome consists of 24 scaffolds of 5,666,696 bp (47.3\% GC content) and an N50 of 5,594,916 bp. In total, 5,494 genes were predicted, 5,417 of which are (Figure 3) protein-coding genes. 4569 of protein coding genes were assigned to a putative function with the remaining annotated as hypothetical proteins. The properties and the statistics of the genome are summarized in Tables 3, 4 and (Additional file 1: Table S1).

\section{Insights from the genome sequence}

Orthologs to other Desulfitobacterium species were determined via bidirectional BLAST hits [43] with at least $70 \%$ sequence identity and similar size of both sequences (+/-5\%).

Two reductive dehalogenase genes (DPCES_1664 and DPCES_3087) are encoded on the genome of $D$. hafniense PCE-S. The latter is the characterized PCE reductive dehalogenase PceA [3]. It is $97 \%$ identical (amino acid sequence) to PceA (DSY_2839) from D. hafniense Y51, which is located on a transposon. This transposon structure is also found in D. hafniense TCE1, where it has been shown to be rapidly lost when the organism is grown in the absence of PCE, leading to the loss of the ability to dechlorinate PCE [45]. The transposon containing pceA of $D$. hafniense PCE-S shows a different structure than the one of D. hafniense Y51 and TCE1 (Figure 4).

Despite the different organization of this transposon, $D$. hafniense PCE-S also loses the ability to dechlorinate PCE after prolonged cultivation in the absence of PCE [15]. The second reductive dehalogenase gene (DPCES_1664) has no ortholog in Y51. A truncated ortholog is encoded in DCB-2 (Dhaf_2620). In D. hafniense DCB-2, the corresponding $r d h A$ gene is truncated n-terminally (50 amino acids) due to the insertion of a stop codon through a frameshift mutation. It seems likely that the gene product of DPCES_1664 is responsible for the partial dechlorination of pentachlorophenol and 2,4,5trichlorophenol by $D$. hafniense PCE-S.

Of the 5,417 protein coding sequences found in the genome of $D$. hafniense PCE-S, 4,402 are orthologous to

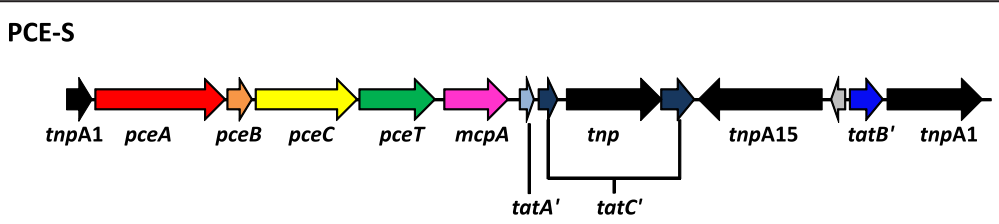

DCA1
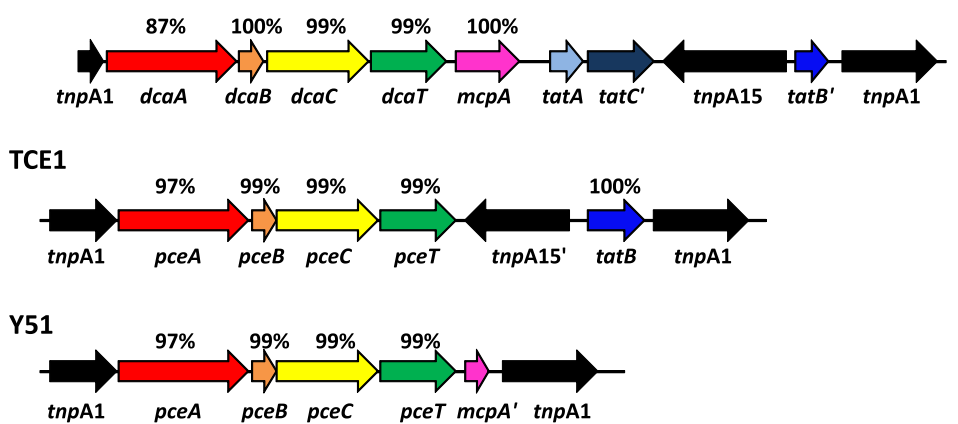

Figure 4 Comparison of transposons carrying $p c e A$ or $d c a A$ from different Desulfitobacterium species and strains. Values given above the CDS arrows are percentage amino acid identity to the respective PCE-S homologs. Modified and updated after [45]. 
proteins encoded in either Y51 or DCB-2. D. hafniense PCE-S harbours six putative phage regions, of which one was classified as a complete prophage, as detected by PHAST [46]. This is opposed to D. hafniense DCB-2 or Y51, where four (DCB-2) and three (Y51) prophages were identified by PHAST as incomplete or questionable, but none as complete. The complete prophage found in $D$. hafniense PCE-S shows highest similarities to Vibrio phage X29 (NCBI RefSeq accession no. NC_024369). Several enzymes, of which orthologs fulfill a catabolic function, are not encoded in $D$. hafniense Y51 and DCB-2, but found on the genome of D. hafniense PCE-S: An ethanolamine ammonia lyase system (PCES_2016-2020), three molybdopterin oxidoreductase gene clusters (DPCES_4294-6, DPCES_4565-7, DPCES_4582-4), together with a molybdopterin import cluster (DPCES_0024-6), and a protein annotated as cellulose synthase (DPCES_2599). A cluster encoding polysaccharide synthesis enzymes (DPCES_3251 to 3245) might be responsible for the biosynthesis of the slime sacculus of PCE-S.

Five CRISPR regions with a length from 958 to $3415 \mathrm{bp}$ and 14 to 51 spacers were identified in the genome of D. hafniense PCE-S with CRISPR finder [47]. This is similar to the situation in DCB-2, where five CRISPR regions with a length of 7 to 60 spacers were found, and in Y51, where five CRISPR regions with a length of 12 to 47 spacers were found. The CRISPR regions in all Desulfitobacterium spp. genomes are located in close proximity to each other, separated by not more than $30 \mathrm{~kb}$ which are to a large extent covered by CRISPR associated (CAS) proteins.

\section{Conclusions}

Taken together, the genome sequence of Desulfitobacterium hafniense PCE-S expands our view on these environmentally interesting microorganisms. The genome sequence gives us insight into the putative chlorophenol dechlorinating activity of a reductive dehalogenase not studied before and might aid bioremediation of chlorinated phenols in the future.

\section{Additional file}

Additional file 1: Table S1. Associated MIGS Record.

\section{Abbreviations}

PCE: Perchloroethylene or tetrachloroethene; TCE: Trichloroethene; DCE: cis-1,2-dichloroethene.

\section{Competing interests}

The authors declared that they have no competing interests.

\section{Authors' contributions}

TG and GD initiated and supervised the study. TG, BH and TK drafted the manuscript and annotated the genome. AR conducted the wetlab work, MW performed electron microscopy. BH and PJS worked on genome sequencing and assembly. TG, BH, TK, HS and GD discussed, analyzed the data and revised the manuscript. All authors read and approved the final manuscript

\section{Acknowledgement}

We would like to thank Heidrun Scholz-Muramatsu and Silke Granzow for initial work on isolation and characterization of D. hafniense PCE-S. The work was funded by the German Research Foundation (DFG research unit FOR 1530). Work of HS and TK was financially supported by the EcoLinc Project of the Netherlands Genomics Initiative, as well as the European Community program FP7 (grants KBBE-211684; BACSIN, and KBBE-222625; METAEXPLORE). $\mathrm{BH}$ is supported by Wageningen University and the Wageningen Institute for Environment and Climate Research (WIMEK) through the IP/OP program Systems Biology (project KB-17-003.02-023).

\section{Author details}

${ }^{1}$ Institut für Mikrobiologie, Lehrstuhl für Angewandte und Ökologische Mikrobiologie, University of Jena, Philosophenweg 12, Jena D-07743, Germany. ${ }^{2}$ Laboratory of Microbiology, Wageningen University, Wageningen 6703 HB, The Netherlands. ${ }^{3}$ Laboratory of Systems and Synthetic Biology, Wageningen University, Wageningen 6703 HB, The Netherlands. ${ }^{4}$ Electron Microscopy Center of the University Hospital Jena, Friedrich Schiller University, Jena, Germany.

Received: 26 September 2014 Accepted: 4 December 2014 Published: 24 February 2015

\section{References}

1. Nonaka H, Keresztes G, Shinoda Y, Ikenaga Y, Abe M, Naito K, et al. Complete genome sequence of the dehalorespiring bacterium Desulfitobacteriumhafniense Y51 and comparison with Dehalococcoides ethenogenes 195. J Bacteriol. 2006;188:2262-74.

2. Kim SH, Harzman C, Davis JK, Hutcheson R, Broderick JB, Marsh TL, et al. Genome sequence of Desulfitobacterium hafniense DCB-2, a Gram-positive anaerobe capable of dehalogenation and metal reduction. BMC Microbiol. 2012;12:21.

3. Miller E, Wohlfarth G, Diekert G. Purification and characterization of the tetrachloroethene reductive dehalogenase of strain PCE-S. Arch Microbiol. 1998;169:497-502.

4. Ye L, Schilhabel A, Bartram S, Boland W, Diekert G. Reductive dehalogenation of brominated ethenes by Sulfurospirillum multivorans and Desulfitobacterium hafniense PCE-S. Environ Microbiol. 2010;12:501-9.

5. Cichocka D, Siegert M, Imfeld G, Andert J, Beck K, Diekert G, et al. Factors controlling the carbon isotope fractionation of tetra- and trichloroethene during reductive dechlorination by Sulfurospirillum ssp. and Desulfitobacterium sp. strain PCE-S. FEMS Microbiol Ecol. 2007;62:98-107.

6. Miller E, Wohlfarth G, Diekert G. Comparative studies on tetrachloroethene reductive dechlorination mediated by Desulfitobacterium sp. strain PCE-S. Arch Microbiol. 1997;168:513-9.

7. Tamura K, Stecher G, Peterson D, Filipski A, Kumar S. MEGA6: Molecular Evolutionary Genetics Analysis version 6.0. Mol Biol Evol. 2013;30:2725-9.

8. Neumann A, Engelmann T, Schmitz R, Greiser Y, Orthaus A, Diekert G. Phenyl methyl ethers: novel electron donors for respiratory growth of Desulfitobacterium hafniense and Desulfitobacterium sp strain PCE-S. Arch Microbiol. 2004;181:245-9.

9. Mingo FS, Studenik S, Diekert G. Conversion of phenyl methyl ethers by Desulfitobacterium spp. and screening for the genes involved. FEMS Microbiol Ecol. 2014.

10. Woese CR, Kandler O, Wheelis ML. Towards a natural system of organisms: proposal for the domains Archaea, Bacteria, and Eucarya. Proc Natl Acad Sci U S A. 1990;87:4576-4579.

11. Gibbons N, Murray R. Proposals concerning the higher taxa of bacteria. Int J Syst Evol Microbiol. 1978;28:1-6.

12. List no. 132. List of new names and new combinations previously effectively, but not validly, published. Int J Syst Evol Microbiol. 2010;60:469-472.

13. Rainey FA: Class II. Clostridia class nov. In Bergey's Manual of Systematic Bacteriology. Vol. 3. 2 edition. Edited by. De Vos P, Garrity G, Jones D, Krieg NR, Ludwig W, Rainey FA, Schleifer KH, Whitman WB. New York: Springer Verlag; 2009:736.

14. Skerman V, Mcgowan V, Sneath P. Approved lists of bacterial names. Int J Syst Evol Microbiol. 1980;30:225-420. 
15. Rogosa M. Peptococcaceae, a new family to include the Gram-positive, anaerobic cocci of the genera Peptococcus, Peptostreptococcus and Ruminococcus. Int J Syst Bacteriol. 1971;21:234-237.

16. Utkin I, Woese C, Wiegel J. Isolation and characterization of Desulfitobacterium dehalogenans gen. nov., sp. nov., an anaerobic bacterium which reductively dechlorinates chlorophenolic compounds. Int J Syst Bacteriol. 1994;44:612-9.

17. Christiansen N, Ahring B. Desulfitobacterium hafniense sp nov, an anaerobic, reductively dechlorinating bacterium. Int J Syst Bact. 1996;46:442-8.

18. Ashburner M, Ball CA, Blake JA, Botstein D, Butler H, Cherry JM, et al. Gene ontology: tool for the unification of biology. The Gene Ontology Consortium. Nat Genet. 2000;25:25-9.

19. Richter M, Rossello-Mora R. Shifting the genomic gold standard for the prokaryotic species definition. Proc Natl Acad Sci U S. 2009;106:19126-31.

20. Field D, Garrity G, Gray T, Morrison N, Selengut J, Sterk P, et al. The minimum information about a genome sequence (MIGS) specification. Nat Biotechnol. 2008;26:541-7.

21. Scholz-Muramatsu H, Neumann A, Messmer M, Moore E, Dieker G. Isolation and characterization of Dehalospirillum multivorans gen. nov., sp. nov., a tetrachloroethene-utilizing, strictly anaerobic bacterium. Arch Microbiol. 1995;163:48-56.

22. Reinhold A, Westermann M, Seifert J, von Bergen M, Schubert T, Diekert G. Impact of Vitamin B-12 on Formation of the Tetrachloroethene Reductive Dehalogenase in Desulfitobacterium hafniense Strain Y51. Appl Environ Microbiol. 2012;78:8025-32.

23. Hernandez D, Francois P, Farinelli L, Osteras M, Schrenzel J. De novo bacterial genome sequencing: millions of very short reads assembled on a desktop computer. Genome Res. 2008;18:802-9.

24. Boisvert S, Laviolette F, Corbeil J. Ray: simultaneous assembly of reads from a mix of high-throughput sequencing technologies. J Comput Biol. 2010;17:1519-33.

25. Zorro - The masked assembler http://ge.ibi.unicamp.br/zorro/.

26. Gao S, Sung WK, Nagarajan N. Opera: reconstructing optimal genomic scaffolds with high-throughput paired-end sequences. J Comput Biol. 2011;18:1681-91.

27. Langmead B, Trapnell C, Pop M, Salzberg SL. Ultrafast and memory-efficient alignment of short DNA sequences to the human genome. Genome Biol. 2009;10:R25

28. Walker BJ, Abeel T, Shea T, Priest M, Abouelliel A, Sakthikumar S, et al. Pilon: An Integrated Tool for Comprehensive Microbial Variant Detection and Genome Assembly Improvement. PLoS ONE. 2014;9(11):e112963. doi:10.1371/journal.pone.0112963.

29. Langmead B, Salzberg SL. Fast gapped-read alignment with Bowtie 2. Nat Methods. 2012;9:357-9.

30. Li H, Handsaker B, Wysoker A, Fennell T, Ruan J, Homer N, et al. The Sequence Alignment/Map format and SAMtools. Bioinformatics. 2009;25:2078-9.

31. Altschul SF, Gish W, Miller W, Myers EW, Lipman DJ. Basic Local Alignment Search Tool. J Mol Biol. 1990;215:403-10.

32. Galardini M, Biondi EG, Bazzicalupo M, Mengoni A. CONTIGuator: a bacterial genomes finishing tool for structural insights on draft genomes. Source Code Biol Med. 2011;6:11.

33. Darling AE, Mau B, Perna NT. ProgressiveMauve: multiple genome alignment with gene gain, loss and rearrangement. PLoS One. 2010;5:e11147.

34. Milne I, Stephen G, Bayer M, Cock PJ, Pritchard L, Cardle L, et al. Using Tablet for visual exploration of second-generation sequencing data. Brief Bioinform. 2013;14:193-202.

35. Hyatt D, Chen GL, Locascio PF, Land ML, Larimer FW, Hauser L. Prodigal: prokaryotic gene recognition and translation initiation site identification. BMC Bioinformatics. 2010;11:119.

36. Hunter S, Jones P, Mitchell A, Apweiler R, Attwood TK, Bateman A, et al. InterPro in 2011: new developments in the family and domain prediction database. Nucleic Acids Res. 2012;40:D306-312.

37. Lowe TM, Eddy SR. Trnascan-SE - a program for improved detection of transfer RNA genes in genomic sequence. Nucleic Acids Res. 1997;25(5) 0955-964. doi:10.1093/nar/25.5.0955

38. Lagesen $\mathrm{K}$, Hallin P, Rodland EA, Staerfeldt HH, Rognes T, Ussery DW RNAmmer: consistent and rapid annotation of ribosomal RNA genes. Nucleic Acids Res. 2007;35:3100-8.

39. Suzek BE, Huang H, McGarvey P, Mazumder R, Wu CH. UniRef: comprehensive and non-redundant UniProt reference clusters. Bioinformatics. 2017;23:1282-1288.
40. UniProt-Consortium. Activities at the universal protein resource (UniProt). Nucleic Acids Res. 2014;42:D191-D198.

41. Morgat A, Coissac E, Coudert E, Axelsen KB, Keller G, Bairoch A, et al. UniPathway: a resource for the exploration and annotation of metabolic pathways. Nucleic Acids Res. 2012;40:D761-769.

42. Claudel-Renard C, Chevalet C, Faraut T, Khan D. Enzyme-specific profiles for genome annotation - PRIAM. Nucleic Acids Reseach. 2003;31:6633-9.

43. Overbeek R, Fonstein M, D'Souza M, Pusch GD, Maltsev N. The use of gene clusters to infer functional coupling. Proc Natl Acad Sci U S A. 1990;96:2896-901.

44. Alikhan NF, Petty NK, Ben Zakour NL, Beatson SA. BLAST Ring Image Generator (BRIG): simple prokaryote genome comparisons. BMC Genomics. 2011;12:402.

45. Duret A, Holliger C, Maillard J. The Physiological Opportunism of Desulfitobacterium hafniense Strain TCE1 towards Organohalide Respiration with Tetrachloroethene. Appl Environ Microbiol. 2012;78:6121-7.

46. Zhou Y, Liang Y, Lynch KH, Dennis JJ, Wishart DS. PHAST: a fast phage search tool. Nucleic Acids Res. 2011;39:W347-352.

47. Grissa I, Vergnaud G, Pourcel C. CRISPRFinder: a web tool to identify clustered regularly interspaced short palindromic repeats. Nucleic Acids Res. 2007;35:W52-57.

\section{doi:10.1186/1944-3277-10-15}

Cite this article as: Goris et al:: Draft genome sequence and

characterization of Desulfitobacterium hafniense PCE-S. Standards in Genomic Sciences 2015 10:15.

\section{Submit your next manuscript to BioMed Central and take full advantage of:}

- Convenient online submission

- Thorough peer review

- No space constraints or color figure charges

- Immediate publication on acceptance

- Inclusion in PubMed, CAS, Scopus and Google Scholar

- Research which is freely available for redistribution 